To read and download this entire book for free, please, visit https://doi.org/10.11647/OBP.0211

\title{
Models in Microeconomic Theory
}

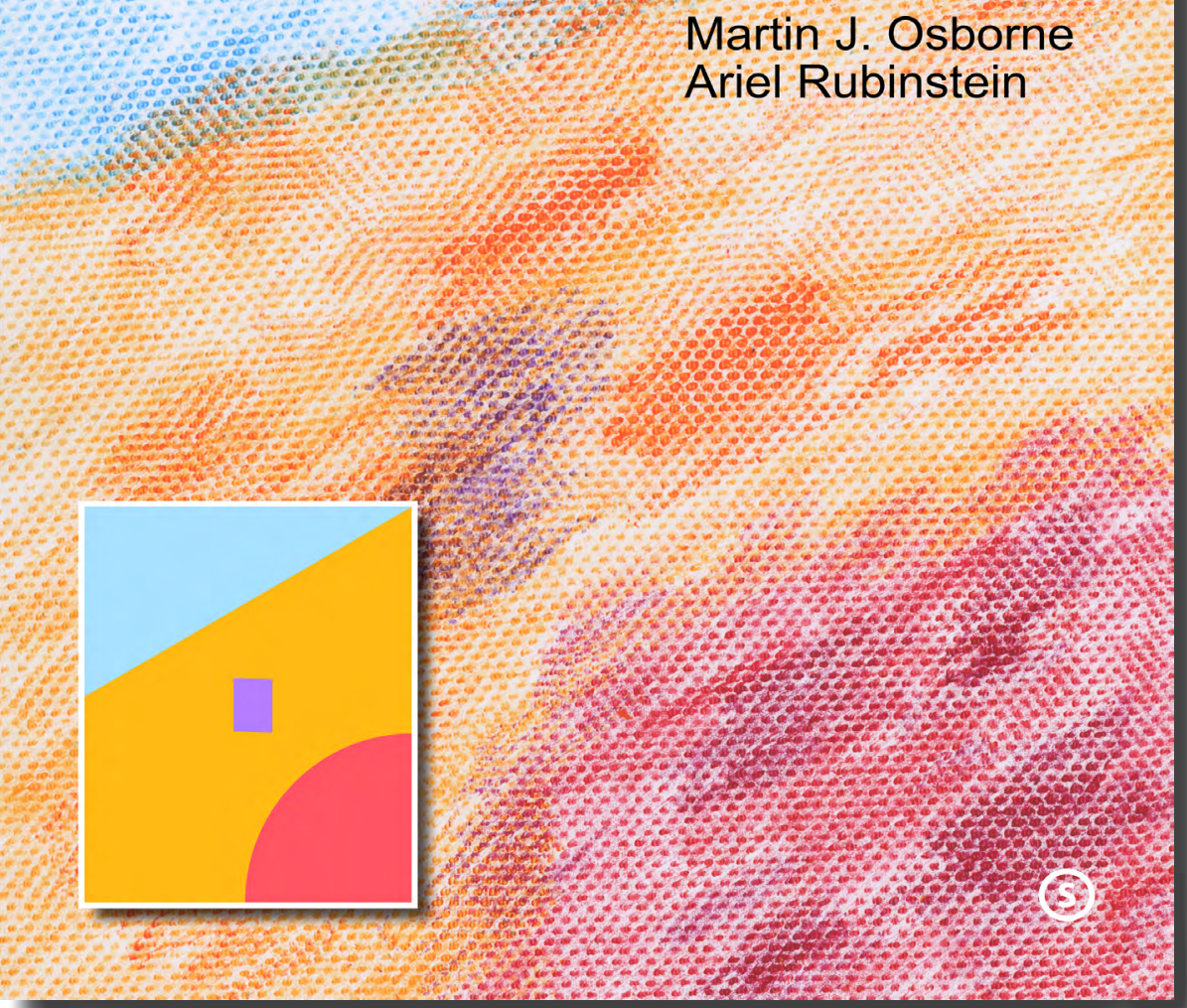

